\title{
Anti-biofilm activity of silver nanoparticles against different microorganisms
}

\author{
Authors: Fidel Martinez-Gutierrez, Laura Boegli, \\ Alessandra Agostinho, Elpidio Morales Sánchez, \\ Horacio Bach, Facundo Ruiz, \& Garth James
}

NOTICE: This is an Accepted Manuscript of an article published in Biofouling on July 2013, available online: http://www.tandfonline.com/10.1080/08927014.2013.794225.

Martinez-Gutierrez F, Boegli L, Agostinho A, Sánchez EM, Bach H, Ruiz F, James G, "Anti-biofilm activity of silver nanoparticles against different microorganisms," Biofouling 2013 29(6):651-60. 


\title{
Anti-biofilm activity of silver nanoparticles against different microorganisms
}

\section{Fidel Martinez-Gutierrez ${ }^{\mathrm{a}}$, Laura Boegli ${ }^{\mathrm{b}}$, Alessandra Agostinho ${ }^{\mathrm{b}}$, Elpidio Morales Sánchez ${ }^{\mathrm{c}}$, Horacio Bach ${ }^{\mathrm{d}}$, Facundo Ruiz ${ }^{\mathrm{e}}$ and Garth James ${ }^{\mathrm{b}}$}

\author{
${ }^{a}$ Facultad de Ciencias Químicas, UASLP, San Luis Potosí, México

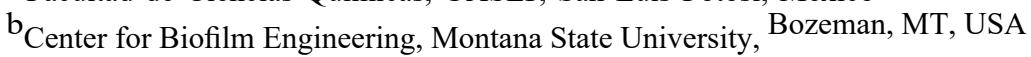 \\ ${ }^{\mathrm{c}}$ Departamento de Físico Matemáticas, Universidad Autónoma de San Luis Potosí, San Luis Potosí, México

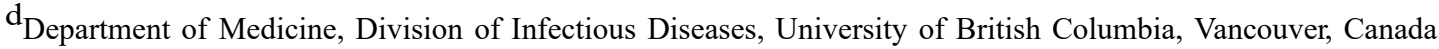 \\ $\mathrm{e}_{\text {Facultad de Ciencias, UASLP, San Luis Potosí, México }}$
}

\begin{abstract}
Biofilms confer protection from adverse environmental conditions and can be reservoirs for pathogenic organisms and sources of disease outbreaks, especially in medical devices. The goal of this research was to evaluate the anti-biofilm activities of silver nanoparticles (AgNPs) against several microorganisms of clinical interest. The antimicrobial activity of AgNPs was tested within biofilms generated under static conditions and also under high fluid shears conditions using a bioreactor. A 4-log reduction in the number of colony-forming units of Pseudomonas aeruginosa was recorded under turbulent fluid conditions in the CDC reactor on exposure to $100 \mathrm{mg} \mathrm{ml} \square 1$ of AgNPs. The antibacterial activity of AgNPs on various microbial strains grown on polycarbonate membranes is reported. In conclusion, AgNPs effectively prevent the formation of biofilms and kill bacteria in established biofilms, which suggests that AgNPs could be used for prevention and treatment of biofilm-related infections. Further research and development are necessary to translate this technology into therapeutic and preventive strategies.
\end{abstract}

Keywords: silver nanoparticles; biofilm; Pseudomonas aeruginosa; CDC reactor; polycarbonate membrane; anti-biofilm activity

\section{Introduction}

Biofilms are microbial consortia embedded in selfproduced exopolymer matrices composed mainly of exopolysaccharides (EPS). Microbes living in these matrices benefit from nutrient and water supplies (Goller \& Romeo 2008); improved lateral gene transfer (Maha \& O'Toole 2001); and protection against adverse environmental conditions, such as desiccation and chemicals, including detergents, disinfectants, and antibiotics (Stewart \& Costerton 2001; Costerton 2007).

Biofilms can also function as reservoirs for pathogenic organisms and sources for disease outbreaks. For instance, biofilms are implicated in otitis media (Bakaletz 2007), otolaryngologic infections (Post et al. 2007), osteomyelitis (Brady et al. 2008), bacterial endocarditis, cystic fibrosis (Høiby 2002), and non-healing wounds (James et al. 2008). Biofilms are also responsible for a wide variety of nosocomial infections. Sources of biofilm-related infections include the surfaces of catheters, medical implants, wound dressings, and other types of medical devices (Costerton et al. 2003).

Planktonic microorganisms can adhere to surfaces and initiate biofilm formation. These surfaces include medical devices such as urinary and central venous catheters (Jacobsen et al. 2008), contact lenses (Imamura et al.
2008) as well as mechanical heart valves, and endotracheal tubes (Lynch \& Robertson 2008). These devices are particularly susceptible to biofilm formation because immune responses are markedly reduced in proximity to foreign bodies. In addition, biofilms prevent the phagocytosis of bacteria by phagocytes and limit the access for antibodies (Donlan \& Costerton 2002; Cerca et al. 2006). The formation of biofilms is also a major cause of implant failure and often limits the lifetime of many indwelling medical devices (Lynch \& Robertson 2008).

Treatment of an infection with current remedies is frequently futile after the biofilm is established. Often, the only solution is physical removal of the biofilm or implant, which is both costly and traumatic to the patient (Lynch \& Robertson 2008).

In recent years, the application of nanoparticles (NPs) in various fields has expanded considerably. NPs have been used successfully in medical and pharmaceutical nanoengineering for the delivery of therapeutic agents (Zhang et al. 2008), in chronic disease diagnostics, and in sensors (Hong et al. 2008). Silver nanoparticles (AgNPs) can already be found in a number of commercial products including food packing materials and kitchen appliances, and are even sold as an alternative 'health supplement' (Chaudhry et al. 2008). Furthermore, AgNPs 
are considered as a potential additive to animal feed to replace antibiotics (Ahmadi 2009). In addition, AgNPs have been examined for their ability to reduce microbial infections in skin (Paddle-Ledinek et al. 2006) and bum wounds (Ulkur et al. 2005), and also to prevent bacterial colonization on various surface devices such as catheters (Maki 2010) and prostheses (Gosheger et al. 2004).

AgNPs are efficient non-specific antimicrobial agents against the growth of a broad spectrum of bacterial and fungal species in planktonic form (Kim et al. 2007; Martínez-Gutierrez et al. 2010). Their antimicrobial activities are attributed to the unique physico-chemical characteristics of AgNPs, such as the high surface area, mass ratio, high reactivity, and sizes in the nanometer range, which confer on them a major advantage for the development of alternative products against multi-drug resistant microorganisms (Martínez-Gutierrez et al. 2012).

Although the cytotoxic mechanism(s) of AgNP have not yet been elucidated fully, one of the main mechanisms may be the release of $\mathrm{Ag}^{+}$ions from the NPs as a result of their exposure to reactive entities generated intracellularly. These reactive entities include highly reactive oxygen and nitrogen species that can corrode, degrade, or dissolve the NPs into their constituents atoms. $\mathrm{Ag}^{+}$ions are detrimental to biomolecules, interfering with normal metabolic reactions and potentially destabilizing the membranes necessary for maintaining cellular integrity (Park et al. 2011). Moreover, as a result of $\mathrm{Ag}^{0}$ ionization, $\mathrm{Ag}^{+}$ions can also interact with proteins, specifically with reactive thiol groups (cysteines), increasing the damage to the cells (Elechiguerra et al. 2005).

The diffusivity of NPs is a parameter which controls the mobility, aggregation, and toxicity of these composites. The diffusion of NPs may be hindered by: (1) the porous structure of the biofilm; (2) the local accumulation of NPs by cells, non-diffusing macromolecules, or the polysaccharide matrix; and (3) the adsorption of the solute to freely diffusing species, abiotic particles, or gas bubbles (Stewart 2003). Then, due to the protection offered by the biofilm matrix to the diffusion of antibiotic agents within the exopolymer matrix, the antimicrobial activity of AgNPs was tested in two different conditions: static conditions and under high fluid shears using a bioreactor. Results presented in this study show that AgNPs were able to inhibit the growth of Pseudomonas aeruginosa, and were also lethal to cells inhabiting the biofilm matrix, suggesting that AgNPs can be embedded in medical devices to avoid microbial colonization and the formation of biofilms.

\section{Methods}

\section{Synthesis of AgNPs}

AgNPs were synthesized by dissolving $0.169 \mathrm{~g}$ of $\mathrm{AgNO}_{3}$ in $100 \mathrm{ml}$ of deionized water. Gallic acid $(0.01 \mathrm{~g})$ was dissolved in $10 \mathrm{ml}$ of deionized water and was added to the $\mathrm{AgNO}_{3}$ solution under stirred conditions. The $\mathrm{pH}$ value of the solution was immediately adjusted to 10 . AgNPs were flocculated by adjusting the $\mathrm{pH}$ to 1.5 using $\mathrm{HNO}_{3}$ and the resulting suspension was filtered through a nitrocellulose filter with a pore diameter of $100 \mathrm{~nm}$ (Millipore) in a vacuum filter flask (Nalgene ${ }^{8}$ ). AgNPs retained on the filter were washed with deionized water until a neutral $\mathrm{pH}$ was measured. Finally, AgNPs were collected from the filter and sonicated to re-disperse them in deionized water, and diluted to reach the study concentrations prior to being characterized. AgNP concentrations were prepared by weighing the powder obtained after filtration and washing.

\section{Characterization of the AgNPs}

AgNPs were characterized by UV-vis spectroscopy using a S2000 UV-Vis spectrometer (OceanOptics Inc.; Dunedin, FL, USA); dynamic light scattering (DLS) analysis was performed using a Malvem Zetasizer Nano ZS (Malvem Instruments, Worcestershire, UK) with water as a solvent, and transmission electron microscopy (TEM) analysis was performed on a JEM-1230 (JEOL, Tokyo, Japan) at an accelerating voltage of $100 \mathrm{kV}$. All the characterization analyses were performed on aqueous dispersions of the AgNPs. To determine the stability of AgNPs at the concentrations used in this study, a stability study was performed using AgNPs in their respective liquid media. The hydrodynamic diameter and zeta potential were measured by DLS (as above). These data are presented as the average size (by number) at time zero. Results are expressed as the average \pm SD of three independent experiments.

\section{Culturing of the microorganisms}

The microorganisms, Acinetobacter baumannii (ATCC BAA-1605) and $P$. aeruginosa mPAO1, (obtained from the University of Washington Genome Center www.genome.washington.edu/UWGC), were evaluated as representative of Gram-negative bacteria. As representative Gram-positive microorganisms, the strains methicillinresistant Staphylococcus aureus (MRSA) (ATCC 700787) and Streptococcus mutans (ATCC 33535) were evaluated. Candida albicans (ATCC 18804) was used as a representative fungal species. Microorganisms were obtained in freeze-dried form and rehydrated in LuriaBertani broth $(10 \mathrm{~g}$ tryptone, $5 \mathrm{~g}$ yeast extract, $5 \mathrm{~g} \mathrm{NaCl1}^{-1}$; Sigma-Aldrich, St Louis, MO) except for $S$. mutans, which was cultured in trypticase soy broth (TSB, Sigma-Aldrich). C. albicans was grown in Sabouraud dextrose broth (Sigma-Aldrich). Microorganisms were maintained on solidified broth (addition of $1.5 \%$ agar), except for $S$. mutans, which was grown on trypticase soy agar supplemented with $5 \%$ sheep's blood. Bacteria and fungi were propagated by shaking at 37 
and $27^{\circ} \mathrm{C}$, respectively, with the exception of $S$. mutans where cultures were placed in a humidified atmosphere supplemented with $5 \% \quad \mathrm{CO}_{2}$ for $24 \mathrm{~h}$ under static conditions.

\section{Formation of biofilms on membranes}

To determine the antimicrobial activity of AgNPs on established biofilms, polycarbonate membranes $(25 \mathrm{~mm}$ diameter, $0.22 \mathrm{~mm}$ pore size; Osmonics, Inc., Minnetonka, $\mathrm{MN}$ ) were sterilized by UV irradiation ( $10 \mathrm{~min}$ per side) and then placed on the appropriate agar medium. The membranes were inoculated with $10 \mathrm{ml}$ of a diluted stationary phase culture of microorganisms at an optical density of 0.05 at $600 \mathrm{~nm}$ (approximately $1.5 \times 10^{8} \mathrm{ml}^{-1}$ microorganisms).

The agar plates were incubated for $24 \mathrm{~h}$ under the conditions indicated above. After $24 \mathrm{~h}$, the test membranes were transferred to fresh plates, and $100 \mathrm{ml}$ of stable AgNPs in the respective liquid media were added at 4 concentrations $\left(100,250,500\right.$, and $\left.1000 \mathrm{mg} \mathrm{m}^{-1}\right)$. Control membranes with adherent biofilms were transferred to fresh plates and treated with $100 \mathrm{ml}$ of sterile phosphate buffered saline (PBS). All biofilms were treated for $24 \mathrm{~h}$. Experiments were performed in triplicate.

\section{Inhibition of biofilm formation using the colony biofilm model}

The ability of AgNPs to inhibit the formation of bacterial and fungal biofilms was studied by slightly modifying the colony biofilm model (Anderl et al. 2000). Briefly, after membranes had been sterilized by UV exposure and placed on the appropriate agar medium, they were inoculated with $10 \mathrm{ml}$ of diluted planktonic culture and $100 \mathrm{ml}$ of stable AgNPs in the respective liquid medium at the 4 test concentrations $\left(100,250,500\right.$, and $\left.1000 \mathrm{mg} \mathrm{ml}^{-1}\right)$. Control membranes with adherent biofilms were transferred to fresh plates and treated with $100 \mathrm{ml}$ sterile PBS. Plates were incubated for $24 \mathrm{~h}$ in the same conditions as the colony biofilm model. Experiments were performed in triplicate.

\section{The formation of biofilms on coupons}

A biofilm was grown under conditions of high shear in the CDC Biofilm Reactor (CDC-BR) (model CBR 90, Biosurface Technologies Corporation, Bozeman, MT) (Goeres et al. 2005) according to published protocols (ASTM International, 2007). Briefly, the CDC-BR consists of a 11 vessel with 8 polypropylene coupon holders, each of which can accommodate 3 sample coupons $(1.3 \mathrm{~cm}$ diameter). Liquid growth medium enters through the top of the vessel and exits via a side-arm discharge port. A magnetic stirring bar incorporating a mixing blade provides fluid mixing and surface shear creating a turbulent flow (Reynolds no. 800-1850). For these calculations, the bulk fluid was assumed to possess the properties of water at $20^{\circ} \mathrm{C}$ when growing a $P$. aeruginosa biofilm. The Reynolds no. at the interior coupon surface in the $\mathrm{CDC}$ reactor was estimated based upon fluid equations developed for 2 concentric cylinders where the inner cylinder rotates (Characklis 1990).

The reactor was filled with $400 \mathrm{ml}$ of $1 \%$ strength TSB and inoculated with $1 \mathrm{ml}$ of an overnight culture of $P$. aeruginosa. The reactor was maintained in a batch mode (mixed, no flow) for $24 \mathrm{~h}$ at $37^{\circ} \mathrm{C}$. At the end of the first $24 \mathrm{~h}$ flow was started and maintained for another $24 \mathrm{~h}$. After the formation of the biofilms, coupons were removed from the reactor, rinsed with $1 \mathrm{ml}$ of PBS and treated for $24 \mathrm{~h}$ with different concentrations of AgNPs $\left(100,250,500\right.$, and $\left.1000 \mathrm{mg} \mathrm{ml}^{-1}\right)$ which had been diluted with $1 \%$ strength TSB. After the $24 \mathrm{~h}$ exposure to AgNPs, the coupons were rinsed with $1 \mathrm{ml}$ of PBS and analyzed by plate counting. Three coupons from each treatment were used to quantify the number of bacterial cells.

\section{Colony counting}

Membranes and coupons were removed and immersed in $9 \mathrm{ml}$ of Dey/Engley neutralizing broth containing $\left(1^{-1}\right)$ : $5 \mathrm{~g}$ pancreatic digest of casein, $2.5 \mathrm{~g}$ yeast extract, $10 \mathrm{~g}$ dextrose, $1 \mathrm{~g}$ sodium thioglycollate, $6 \mathrm{~g}$ sodium thiosulfate, $2 \mathrm{~g}$ sodium bisulfite, $5 \mathrm{~g}$ polysorbate, $7 \mathrm{~g}$ lecithin, and $0.02 \mathrm{~g}$ bromocresol purple. Biofilms were disaggregated using a sequence of treatments, which included vortexing (Vortex Genie 2; Scientific Products), sonication (model 2510 sonicating water bath; Branson), and vortexing again, alternating $120 \mathrm{~s}$ cycles of sonication at a frequency of $42 \mathrm{kHz}$, with $30 \mathrm{~s}$ vortexing, according to published protocols (Goeres et al. 2005). The suspensions of cells obtained from the biofilms after the disaggregation steps were serially diluted in PBS, plated in triplicate on the appropriate agar medium, and incubated under the conditions stated above. The colony-forming units (CFU) were counted after incubation for $18 \mathrm{~h}$.

\section{Statistical analysis}

The microbial density recorded for each membrane and coupon was $\log 10$-transformed. All statistical calculations were performed on the log density values. For each test, the log densities were converted into a $\log$ reduction measure of efficacy. The $\log$ reduction is the mean $\log$ density for control coupons or membranes minus the mean $\log$ density for the corresponding treated coupons or membranes (Zelver et al. 2001). Statistical significance was determined using a two-tailed $t$-test assuming unequal variances with $\alpha=0.5$. A $p$ value $\leqslant 0.05$ was considered to be significant.

\section{Microscopic imaging of biofilms}

Biofilms of $P$ aeruginosa were used as models for imaging purposes. One coupon from each treatment was 
removed from the reactor and imaged using a confocal scanning laser microscope (Leica AOBS SP2; Leica Microsystem Inc., Buffalo Grove, IL) equipped with a two-photon Mai Tai attachment (Leica Microsystem Inc.). Coupons (one from each treatment) were removed from the reactor, rinsed with $1 \mathrm{ml}$ PBS to remove unattached bacteria, and stained with LIVE/DEAD ${ }^{\infty}$ BacLight $^{\mathrm{TM}}$ Viability Kit (Molecular Probes, Inc.) for $10 \mathrm{~min}$ according to the manufacturer's instructions. This kit consists of two components: SYTO 9 that stains all bacterial cells with a green fluorescence; and propidium iodide, a red fluorescent stain that only penetrates cells with damaged membranes.

\section{Results}

\section{Synthesis and characterization of the AgNPs}

TEM revealed that AgNPs are monodispersed and spherical in shape (Figure 1A). Based on the histogram of the particle size distribution (Figure 1B), which was derived from the corresponding TEM micrograph $(n=106)$, the average size $( \pm \mathrm{SD})$ of $\mathrm{AgNPs}$ was $25.2 \pm 4 \mathrm{~nm}$. The hydrodynamic diameter $( \pm \mathrm{SD})$ of the AgNPs (based on

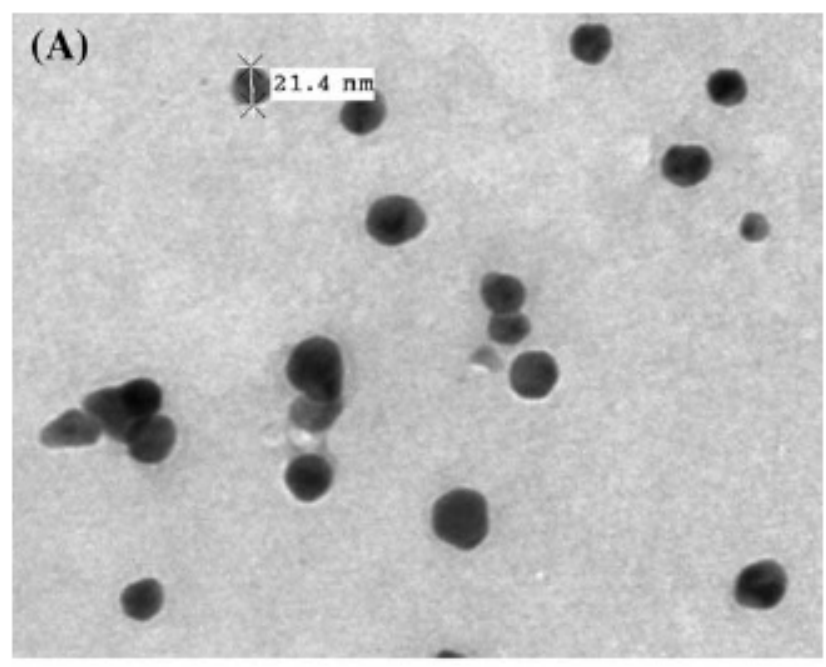

(B)

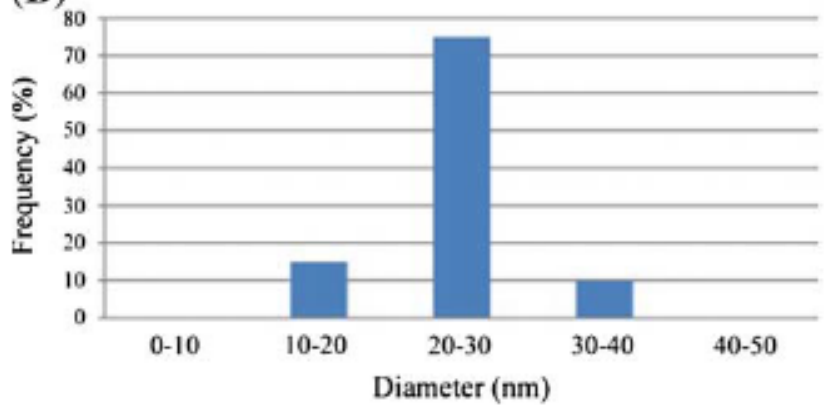

Figure 1. Physico-chemical characteristics of synthesized AgNPs. TEM (A) and size distribution (B) of the nanocomposite synthesized in this work.
Table 1. Physico-chemical characteristics of synthesized AgNPs.

\begin{tabular}{lllr}
\hline & & \multicolumn{2}{c}{ Solution } \\
\cline { 3 - 4 } Parameter & Method & Aqueous & TSB \\
\hline Hydrodynamic & DLS & $28.1 \pm 2.3$ & $54.8 \pm 12.7$ \\
diameter $(\mathrm{nm})$ & TEM & $25.2 \pm 4$ & $25.2 \pm 4.0$ \\
Zeta potential $(\mathrm{mV})$ & DLS & $-40.9 \pm 2.5$ & $-27.2 \pm 6.4$ \\
\hline
\end{tabular}

Note: $\mathrm{DLS}=$ dynamic light scattering, $T E M=$ transmission electron microscopy.

the number distribution) synthesized in aqueous solution was $28.1 \pm 2.3 \mathrm{~nm}$, with a zeta potential of -40.9 $\pm 2.5 \mathrm{mV}$ as measured by DLS $\left(n=1.39 \times 10^{15} \mathrm{NP} \mathrm{ml}^{-1}\right)$. Results of the stability assay show that the AgNPs were stable in the high ionic strength TSB at the concentrations used, because the hydrodynamic size increased to $54.8 \pm 12.7 \mathrm{~nm}$ with a zeta potential of $-27.2 \pm 6.4 \mathrm{mV}$ (Table 1).

\section{Treatment of established biofilms}

The final cell concentration for each microorganism after treatment with AgNPs was compared to the initial number of cells. The established biofilm of Gram-negative microorganisms showed an increased inhibition in the presence of AgNPs.

$P$. aeruginosa was the most susceptible microorganism with a 2-log reduction in the number of CFU (Table 2). The established biofilms showed a high resistance to the action of the AgNPs; inhibition by AgNPs at the lower concentrations of 500 and $250 \mathrm{mg} \mathrm{m}^{-1}$ was $\sim 1$-log reduction for Gram-negative and $<0.5$-log reduction for Gram-positive microorganisms.

\section{Inhibition of biofilm growth}

The inhibition of the growth of microorganisms in a biofilm by AgNPs was evaluated for bacterial strains able to colonize medical devices, such as $P$. aeruginosa, A. baumannii, and MRSA. In addition, $S$. mutans and C. albicans were tested because they are major cariogenic and periodontopathogenic pathogens in formed oral biofilms, respectively.

The exposure of microorganisms to AgNPs resulted in the inhibition of microbial biofilm development on membranes in a dose-dependent manner (Figure 2A). It is noteworthy that a $\sim 4-\log$ reduction was observed when $P$. aeruginosa was exposed to $500 \mathrm{mg} \mathrm{ml}^{-1}$ AgNPs, whereas a 6-log reduction was observed when the concentration of the AgNPs was increased to $1000 \mathrm{mg} \mathrm{ml}^{-1}$. A. baumannii had a more steady activity with 3.5-4-log reductions being observed when cells were exposed to AgNPs concentrations between 250 and $1000 \mathrm{mg} \mathrm{ml}^{-1}$. Weaker activity was observed with the remaining microbial strains, with only a $1-\log$ reduction 
Table 2. Treatment of established biofilms with AgNP.

\begin{tabular}{lccccr}
\hline & \multicolumn{2}{c}{ AgNP treatment $\left(\mathrm{mg} \mathrm{ml}^{-1}\right)$} & \multicolumn{1}{c}{$\begin{array}{c}\text { Control } \\
\text { PBS }\end{array}$} \\
\cline { 2 - 5 } & 1000 & 500 & 250 & $9.61 \pm 0.10$ & $10.30 \pm 0.13$ \\
$\mathrm{nya}$ & $8.41 \pm 0.01$ & $8.71 \pm 0.01$ & $9.10 \pm 0.02$ & $9.80 \pm 0.27$ & $10.0 \pm 0.51$ \\
$\mathrm{Ab}$ & $8.83 \pm 1.17$ & $9.51 \pm 0.29$ & $9.71 \pm 0.23$ & $9.62 \pm 0.19$ & $9.71 \pm 0.29$ \\
$\mathrm{MRSA}$ & $9.15 \pm 0.07$ & $9.45 \pm 0.08$ & $9.52 \pm 0.11$ & $8.39 \pm 0.06$ & $8.41 \pm 0.05$ \\
$\mathrm{Ca}$ & $8.09 \pm 0.02$ & $8.34 \pm 0.06$ & $8.35 \pm 0.04$ & $9.59 \pm 0.02$ & $9.75 \pm 0.05$ \\
$\mathrm{Sm}$ & $9.17 \pm 0.04$ & $9.48 \pm 0.03$ & $9.59 \pm 0.02$ & & \\
\hline
\end{tabular}

Note: $\mathrm{Pa}=P$. aeruginosa, $\mathrm{Ab}=A$. baumanii, MRSA $=$ methicillin-resistant $S$. aureus, $\mathrm{Ca}=C$. albicans, $\mathrm{Sm}=S$. mutans. Data represent the mean of three independent expariments expressed in decimal $\log a r i t h m(\log 10 \pm S D)$ of CFU.

over all the treatments. Figure 2B shows selected images of microorganisms grown on membranes treated with AgNPs.

\section{CDC-BR method}

$P$. aeruginosa was chosen as the model microorganism to determine the antimicrobial activity of AgNPs against mature biofilms (Goeres et al. 2005) and was grown in a biofilm reactor (CDC-BR). Biofilms were formed on coupon discs within the reactor and then treated with different concentrations of AgNPs. Concentrations of AgNPs as low as $100 \mathrm{mg} \mathrm{ml}^{-1}$ showed a $>4$-log reduction in the number of CFU, while increasing the concentration of AgNPs to $1000 \mathrm{mg} \mathrm{ml}^{-1}$ resulted in a $5.5-\mathrm{log}$ reduction (Figure 3).

\section{Confocal microscope images}

Biofilms of $P$. aeruginosa were imaged by confocal scanning laser microscopy. To assess the antimicrobial activity of AgNPs, samples were stained to differentiate between live and dead bacteria. Red fluorescence indicates cells with compromised membranes (dead), whereas green fluorescence indicates cells with intact membranes (live). At AgNP concentrations of 100 and $250 \mathrm{mg} \mathrm{ml}^{-1}$, only red cells were observed suggesting that most of the microorganisms were killed by the antimicrobial effect of the AgNPs, whereas the untreated control biofilm was mainly composed of live green cells (Figure 4).

\section{Discussion}

Biofilms grow in diverse and dynamic environments where factors such as fluid shear are important. Consequently choosing a method that incorporates those factors as part of the test is essential.

Studies on the antibacterial, antifouling, and anti-biofilm effects of NPs have increased, using both standard and non-standard methods; over the last few years, the incorporation of NPs in new composites has escalated. A sufficient variety of biofilm models are now commercially available or may be constructed in the laboratory. One of the main issues for uninitiated researchers is making a rational choice regarding the best model to use. Generally, systems that closely reproduce in situ conditions should be chosen when the aim is solely to reproduce natural biofilms under laboratory conditions.

Previous studies reported the embedment of AgNPs in new composites generated by acrylamide grafted onto polyethersulfone fibers. The nanocomposite was exposed to a suspension of Escherichia coli and subsequently incubated it for $8 \mathrm{~h}$. The presence of AgNPs in the membrane killed $99.99 \%$ of the microorganisms (Sawada et al. 2012). Other studies reported a 2-log reduction in the number of $E$. coli after filtration of the cells through a polysulfone membrane containing AgNPs at a concentration of $220 \mu \mathrm{g} \mathrm{mg}^{-1}$ (Zodrow et al. 2009). Although in this study $E$. coli was not tested, a similar log reduction was observed for $P$. aeruginosa in the colony biofilm model.

The anti-biofilm activity of AgNPs against $P$. aeruginosa and Staphylococcus epidermidis, two common infectious agents responsible for microbial keratitis, has also been studied (Kalishwaralal et al. 2010). AgNPs with an average size of $50 \mathrm{~nm}$ at concentrations of $100 \mathrm{nM}$ were able to inhibit the formation of biofilms by Gram-negative and Gram-positive microorganisms almost equally (Kalishwaralal et al. 2010). In the present study, AgNPs synthesized using environmentally benign solvents showed better inhibition of the Gram-negative microorganisms $c f$. Grampositive bacteria and C. albicans.

The use of other NPs to inhibit the development of biofilms has also been reported. For instance, ZnO NPs were embedded in polyvinyl chloride, a polymer used in endotracheal tubes and catheters which is frequently subject to microbial infection (Seil \& Webster 2011). That study reported a reduction of $55 \%$ in the development of biofilm of $S$. aureus on the $\mathrm{ZnO}$ nanocomposite (Seil \& Webster 2011). Although the study presented here also reports a reduction in the formation of biofilm, the values reported in different studies cannot be compared because different methods were used to express the results.

The antibacterial activity of superparamagnetic iron oxide nanoparticles (SPIONs) of $\sim 14-18 \mathrm{~nm}$ diameter 


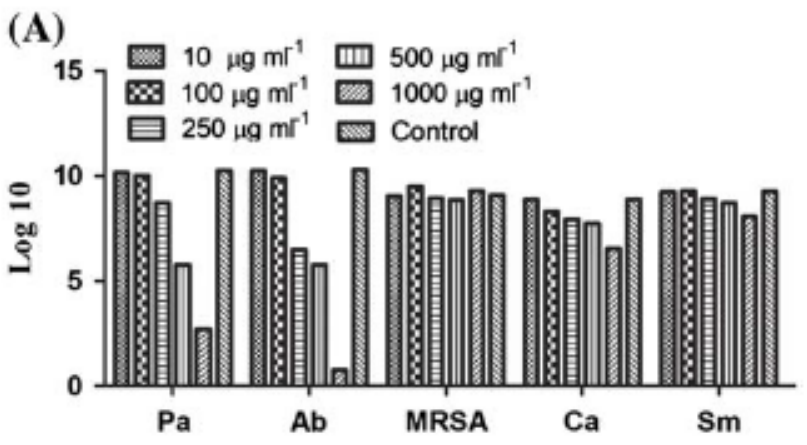

(B)
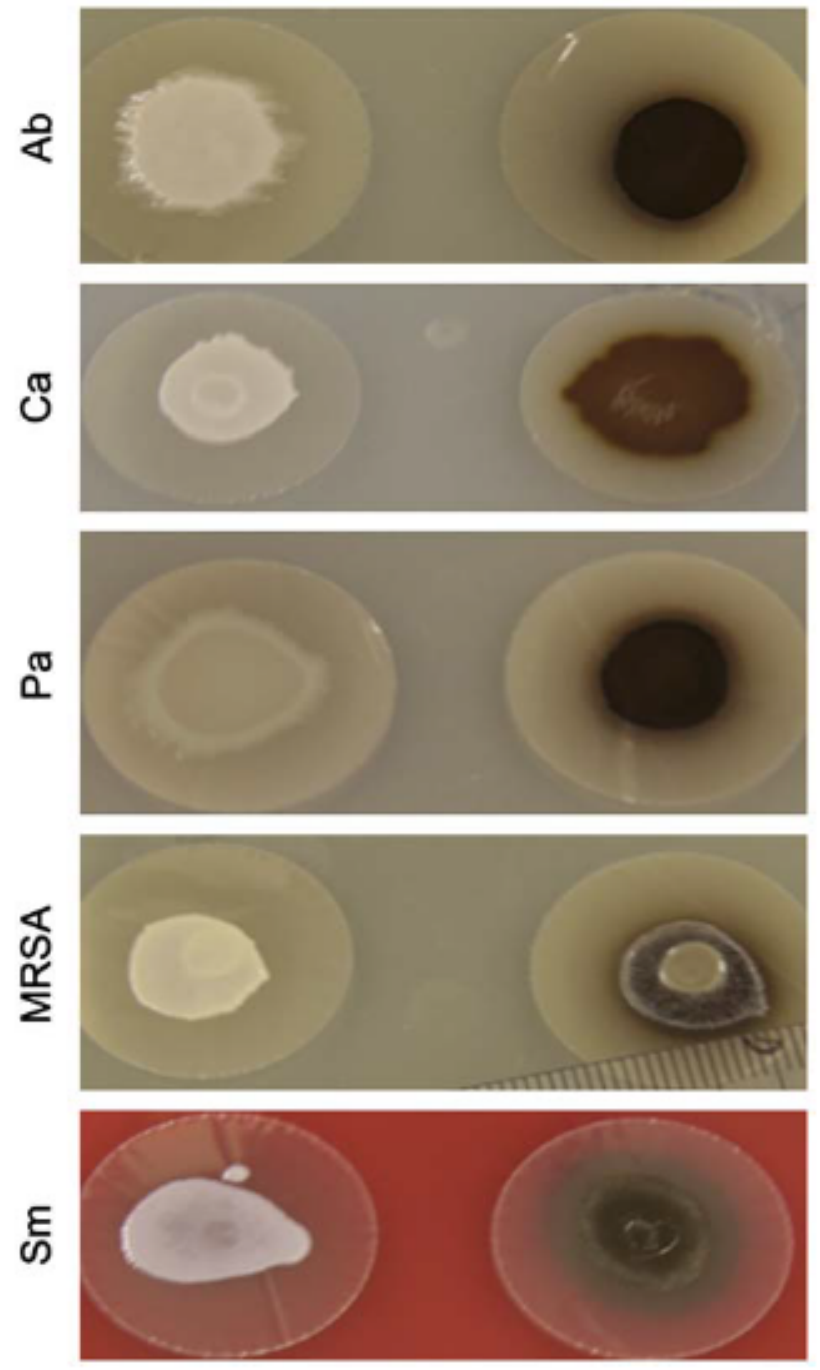

Figure 2. The inhibition of the growth of the biofilm using a colony model. (A) Inhibition of the growth of microorganisms with varying concentrations of AgNPs. (B) Selected images showing the inhibition in the formation of biofilms at a $1000 \mathrm{mg} \mathrm{ml}^{-1}$ concentration of AgNP. Ab, A. baumannii; Ca, C. albicans, MRSA, methicillin-resistant $S$. aureus; $\mathrm{Pa}$, $P$. aeruginosa; $\mathrm{Sm}, S$. mutans.

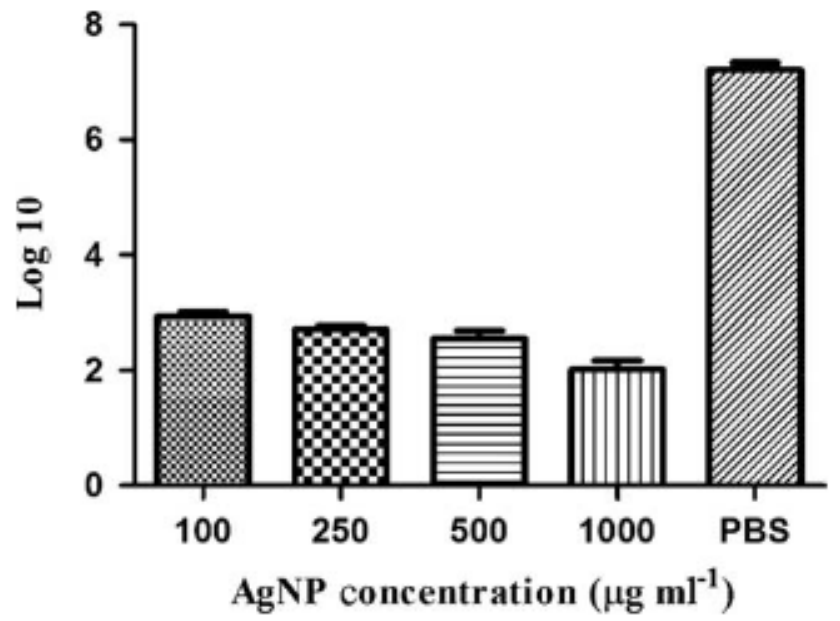

Figure 3. Antimicrobial activities of AgNPs against biofilms formed in the CDC-BR. Biofilms of $P$. aeruginos $a$ were treated with different concentrations of $\mathrm{AgNPS}$ and the survival of bacteria was assessed by counting the CFU. The log reduction was calculated relative to untreated control biofilms. Experiments were performed in triplicate.

was determined against biofilms of gentamicin-resistant $S$. aureus and S. epidermidis (Subbiahdoss et al. 2012). The authors reported an increased antibacterial activity of $\sim 10 \%$ against $S$. aureus, and between 10 and $15 \%$ against $S$. epidermidis when SPIONS were grafted with materials such as carboxyethylsilanetriol, aminopropyltriethoxysilane, and aminopolyethylene glycol (Subbiahdoss et al. 2012). Again, since the results were presented in percentage mortality and not as the reduction in the number of bacteria, results cannot be compared directly to the study presented here, where reductions of several fold were observed. Further development of SPIONs resulted in the generation of engineered magnetic goldcoated, silver-coated, or silver-gold-coated NPs. Interestingly, SPION silver and SPION silver-gold NPs caused $\sim 40-50 \%$ bacterial mortality within biofilms, whereas an activation of these NPs by the application of a magnetic field showed an increased bacterial mortality up to $\sim 70 \%$ (Mahmoudi \& Serpooshan 2012).

Another study reported the use of a decapeptide to treat biofilms formed by microorganisms inhabiting the buccal environment (Liu et al. 2011). Interestingly, this decapeptide was able to reduce the thickness of a biofilm of $S$. mutans by $\sim 55 \%$ at a concentration of $500 \mathrm{mg} \mathrm{ml}^{-1}$ and significantly reduced the viability of the cells within the biofilm. Here we report similar results for bacterial inhibition by AgNPs at concentrations $\mathrm{P} 250 \mathrm{mg} \mathrm{ml}^{-1}$. From the present study, it is clear that susceptibility to AgNPs is strain dependent, which is in agreement with the results reported for the decapeptide, where antibacterial results varied according to the 


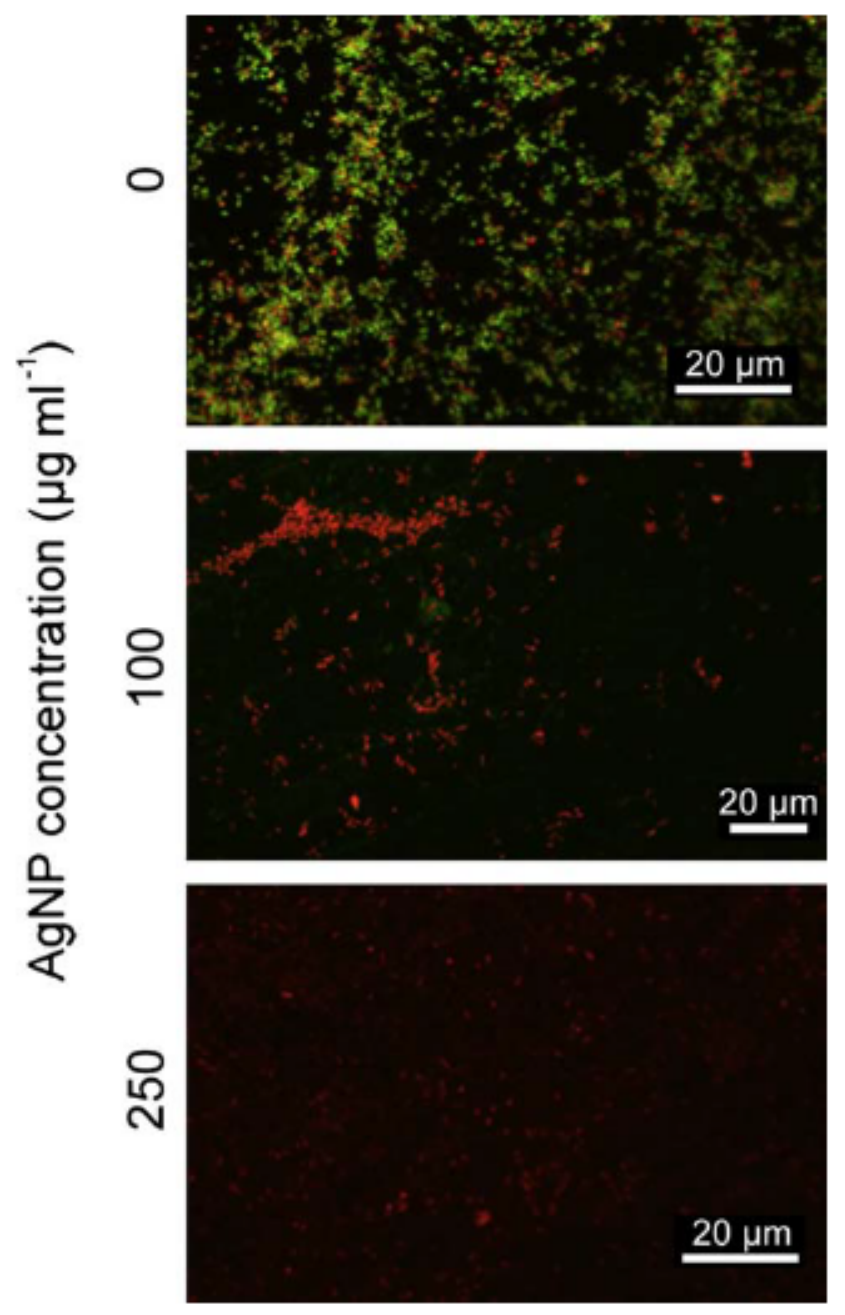

Figure 4. Images of biofilms of $P$. aeruginosa after treatment of the reactor coupons with AgNPs. The LIVE/DEAD BacLight ${ }^{\mathrm{TM}}$ Bacterial Viability Kit was used to image the presence of live and dead cells. Red color indicates dead cells, whereas green color indicates live cells. Scale bars $=20 \mu \mathrm{m}$.

microorganism assayed (Liu et al. 2011). Care is required when interpreting data derived from this type of model since the availability of cationic nutrients, such as iron and magnesium, may be reduced through interaction with the anionic agar polysaccharide gel. The effectiveness of cationic antimicrobials may be affected similarly if these are incorporated into the agar (Sutherland 2001).

For the biofilm of $P$. aeruginosa, the log reductions were inversely related to fluid shear. The biofilms formed in the CDC-BR were inhibited by the AgNPs; a concentration of $100 \mathrm{mg} \mathrm{ml}^{-1}$ resulting in a 4-log reduction. Further reductions were observed when the concentration of AgNPs was increased to $1000 \mathrm{mg} \mathrm{ml}^{-1}$ (5.5-log reduction). Interestingly, a similar $\log$ reduction $(6-\log )$ was observed when biofilms of $P$. aeruginos $a$ were developed on membranes at a AgNP concentration of $1000 \mathrm{mg} \mathrm{m}^{-1}$. These results are in line with previous studies reporting that biofilms grown in turbulent flow conditions showed more mass, resulting in an increase of the density, physiological activity, and total protein when compared to biofilms generated under static conditions (BuckinghamMeyer et al. 2007). However, at lower concentrations of AgNPs, the reduction in biofilm on the membrane was not exceptional when compared to the reactor results at the same concentrations of AgNPs. This difference can be explained as a result of biofilm formation under shear forces (within the reactor), which is a complex and dynamic process that can change the structure and permeability of biofilms depending on the reactor conditions. For example, studies have shown that high shear forces can change the biofilm to a thinner and denser structure (Vieira et al. 1993), which would affect directly the mass transfer of nutrients or particles as a result of an increasing hydrodynamic turbulence (Wasche et al. 2000). Thus, as a result of an increase in the thickness of the biofilm, mass transfer becomes a factor that forces bacteria to adapt to those limitations (Stewart \& Franklin 2008). Those adaptions include a subsequent change to adopt a less dense structure (Teodosio et al. 2011), including the formation of liquid channels as demonstrated in strains of Pseudomonas sp. and Klebsiella sp. (Stoodley et al. 1994) or to promote an increase in the biofilm thickness with a concomitant reduction in the mechanical strength which would facilitate access to nutrients and allow particles into biofilm structures (Teodosio et al. 2011). Another explanation may be related to a change in the morphology of the bacteria as shown in the formation of biofilm of $P$. aeruginosa under shear stress and antibiotics (Fonseca \& Sousa 2007). Although antibiotics were not used in the system described in the present study, the behavior of AgNPs as antimicrobial agents and as potential modifiers of the bacterial cell wall should be taken in account.

The anti-biofilm activity of AgNPs against the strains tested shows a less significant effect on the growth of Gram-positive bacteria than on that of Gram-negative bacteria $(p=0.05)$. This observation may be a result of the structural differences in the composition of the cell wall of Gram-positive vs Gram-negative bacteria, although it has been reported that bacteria belonging to both groups exhibit equal mortality to AgNPs (Fayaz et al. 2010). Another possible mechanism by which AgNPs (Ag 0 metallic and $\mathrm{Ag}^{+}$ions) reduce the formation of biofilms is an interference or inhibition and/or regulation of EPS. For example, the production of EPS by $P$. aeruginosa is controlled by a gene cluster of 15 genes (Matsukawa \& Greenberg 2004) and a potential inhibition of proteins by AgNPs will impair the synthesis of EPS.

The mechanism accounting for the deactivation of proteins may be explained by a reactive attachment of $\mathrm{Ag}^{+}$ions to the cysteine residues present in proteins. This was demonstrated by exposing the human hepatome HepG2 cells to N-acetyl-cysteine (NAC), an antioxidant 
and glutathione precursor prior to exposure to AgNPs. The results of this study showed that the NAC treatment was equivalent to the untreated controls (Kim et al. 2009). Then, as a result of an ionization of the AgNPs, $\mathrm{Ag}^{+}$ions can interact with protein and enzyme thiol groups, such as cysteines producing further damage (Elechiguerra et al. 2005).

The use of the CDC-BR is favored because it is a standard protocol (ASTM 2562-07) which has been evaluated systematically. When operated according to standard procedures, the CDC-BR has been shown to be reliable and is relatively insensitive to minor variations in the time allowed for initial surface colonization, culture temperature, nutrient concentration, and fluid shear stress (Goeres et al. 2005). In fact, it provides reproducible samples of biofilm under consistent growth conditions for the evaluation of antimicrobial agents and surface materials.

Biofilms increase the antibiotic tolerance of microorganisms, making it very difficult to control infections. For example, tobramycin and ciprofloxacin were able to penetrate biofilms formed by Pseudomonas sp. in a biofilm reactor, but were not lethal to the bacteria (Walters et al. 2003). Results from the present study show that AgNPs are lethal to bacteria associated with a biofilm. Further studies are needed to investigate the role of $\mathrm{Ag}^{+}$ ions in toxicity of $\mathrm{AgNP}$ and their diffusion through the biofilm. Higher concentrations of AgNPs (100-1000 times) are necessary to kill microbes within biofilms as compared to concentrations needed to kill planktonic forms (Martínez-Gutierrez et al. 2012). Those results are coincident with the previous work of Ashkarran et al. (2012), which concluded that AgNPs should have dual toxicity effects (high toxicity to bacteria and no/low toxicity (biocompatible) to human cells). The scientific community faces various challenges in helping to support the nanotechnology industry in minimizing the risks and maximizing the benefits from these technologies.

AgNPs covering the surfaces would provide great potential for prevention and treatment of these infections related to biofilm formation, and functionalization of AgNPs should help to maintain the desired properties of the product. However, further research and development are necessary to translate this technology into therapeutic and preventive strategies, because Prabhakara et al. (2011) reported that medical grade polyurethane coated with polyanilines and AgNPs $(\sim 22 \mathrm{~nm})$ reduced the attachment of $P$. aeruginosa and Bacillus subtilis by only $\sim 1$ and $0.5-\log$, respectively.

\section{Conclusions}

AgNPs effectively prevent the formation of biofilms and are lethal to bacteria in established biofilms, which suggests that they can be embedded into the matrices or material used for the fabrication of medical devices to avoid the adherence, colonization and the formation of microbial biofilms on the surfaces of those devices. Further research and development are necessary to translate this technology into therapeutic and preventive strategies.

\section{Acknowledgments}

This study was supported by the Center for Biofilm Engineering (CBE), Montana State University, Bozeman, MT, USA. The authors thank Drs J. William Costerton and Philip S. Stewart for their support in this project. Jeffrey Helm is also acknowledged for helpful discussions.

\section{References}

Ahmadi J. 2009. Application of different levels of silver nanoparticles in food on the performance and some blood parameters of broiler chickens. World Appl Sci J. 7:24-27.

Anderl JN, Franklin MJ, Stewart PS. 2000. Role of antibiotic penetration limitation in Klebsiella pneumoniae biofilm resistance to ampicillin and ciprofloxacin. Antimicrob Agents Chemother. 44:1818-1824.

Ashkarran AA, Ghavami M, Aghaverdi H, Stroeve P, Mahmoudi M. 2012. Bacterial effects and protein corona evaluations: crucial ignored factors in the prediction of bio-efficacy of various forms of silver nanoparticles. Chem Res Toxicol. 6:1231-1242.

ASTM International. 2007. E-2562-07: standard test method for quantification of a Pseudomonas aeruginosa biofilm grown with shear and continuous flow using a rotating disk reactor. Annual book of ASTM standards, vol. 11.05. West Conshohocken (PA): ASTM International.

Bakaletz LO. 2007. Bacterial biofilms in otitis media: evidence and relevance. Pediatr Infect Dis J. 26:S17-S19.

Brady RA, Leid JG, Calhoun JH, Costerton JW, Shirtliff ME. 2008. Osteomyelitis and the role of biofilms in chronic infection. FEMS Immunol Med Microbiol. 52:13-22.

Buckingham-Meyer K, Goeres DM, Hamilton MA. 2007. Comparative evaluation of biofilm disinfectant efficacy tests. J Microbiol Methods. 70:236-244.

Cerca N, Jefferson KK, Oliveira R, Pier GB, Azeredo J. 2006. Comparative antibody-mediated phagocytosis of Staphylococcus epidermidis cells grown in a biofilm or in the planktonic state. Infect Immun. 78:4849-4855.

Charack lis WG. 1990. Laboratory biofilm reactors. In: Characklis WG, Marshall KC, editors. Biofilms. New York (NY): John Wiley \& Sons; p. 55-89.

Chaudhry Q, Scotter M, Blackburn J, Ross B, Boxall A, Castle L. 2008. Applications and implications of nanotechnologies for the food sector. Food Addit Contam: Part A: Chem Anal Control Expo Risk Assess. 25:241-258.

Costerton JW. 2007. Bacterial attachment to surfaces. In: Eckey DC, editor. The biofilm primer. Berlin: Springer; p. 36-43.

Costerton W, Veeh R, Shirtliff M, Pasmore M, Post C, Ehrlich G. 2003. The application of biofilm science to the study and control of chronic bacterial infections. J Clin Invest. 112: 1466-1477.

Donlan RM, Costerton JW. 2002. Biofilms: survival mechanisms of clinically relevant microorganisms. Clin Microbiol Rev. 15:167-193. 
Elechiguerra JL, Burt JL, Morones JR, Camacho-Bragado A, Gao X, Lara HH, Yacaman MJ. 2005. Interaction of silver nanoparticles with HIV-1. J Nanobiotechnol. 29:3-6.

Fayaz AM, Balaji K, Girilal M, Yadav R, Kalaichelvan PT, Venketesan R, 2010. Biogenic synthesis of silver nanoparticles and their synergistic effect with antibiotics: a study against Gram-positive and Gram-negative bacteria. Nanomedicine. 6:103-109.

Fonseca AP, Sousa JC. 2007. Effect of shear stress on growth, adhesion and biofilm formation of Pseudomonas aeruginos $a$ with antibiotic-induced morphological changes. Int $\mathbf{J}$ Antimicrob Agents. 30:236-241.

Goeres DM, Loetterle LR, Hamilton MA, Murga R, Kirby DW, Donlan RM. 2005. Statistical assessment of a laboratory method for growing biofilms. Microbiology. 151:757-762.

Goller CC, Romeo T. 2008. Environmental influences on biofilm development. Curr Top Microbiol Immunol, 322:37-66.

Gosheger G, Hardes J, Ahrens H, Streitburger A, Buerger H, Erren M, Gunsel A, Kemper FH, Winkelmann W, Von Eiff C. 2004. Silver-coated megaendoprostheses in a rabbit model-an analysis of the infection rate and toxicological side effects. Biomaterials. 25:5547-5556.

Høiby N. 2002. Understanding bacterial biofilms in patients with cystic fibrosis: current and innovative approaches to potential therapies. J Cyst Fibros. 1:249-254.

Hong B, Kai J, Ren Y, Han J, Zou Z, Ahn CH. 2008. Highly sensitive rapid, reliable, and automatic cardiovascular disease diagnosis with nanoparticle fluorescence enhancer and MEMS. Adv Exp Med Biol. 614:265-273.

Imamura Y, Chandra J, Mukherjee PK, Lattif AA, Szczotka-Flynn LB, Pearlman E, Lass JH, O'Donnell K, Ghannoum MA. 2008. Fusarium and Candida albicans biofilms on soft contact lenses: model development, influence of lens type, and susceptibility to lens care solutions. Antimicrob Agents Chemother. 52:171-182.

Jacobsen SM, Stickler DJ, Mobley HL, Shirtliff ME. 2008. Complicated catheter-associated urinary tract infections due to Escherichia coli and Proteus mirabilis. Clin Microbiol Rev. 21:26-59.

James GA, Swogger E, Wolcott R, Pulcini E, Secor P, Sestrich J, Costerton JW, Stewart PS. 2008. Biofilms in chronic wounds. Wound Repair Regen. 16:37-44.

Kalishwaralal K, BarathManiKanth S, Pandian SR, Deepak V, Gurunathan S. 2010. Silver nanoparticles impede the biofilm formation by Pseudomonas aeruginosa and Staphylocaccus epidermidis. Colloids Surf, B. 79:340-344.

Kim JS, Kuk E, Yu KN, Kim JH, Park SJ, Lee HJ, Kim SH, Park YK, Park YH, Hwang CY, et al. 2007. Antimicrobial effects of silver nanoparticles. Nanomed Nanotechnol Biol Med. 3:95-101.

Kim S, Choi JE, Choi J, Chung KH, Park K, Yi J, Ryu DY. 2009. Oxidative stress-dependent toxicity of silver nanoparticles in human hepatoma cells. Toxicol In Vitro. 23:1076-1084.

Liu Y, Wang L, Zhou X, Hu S, Zhang S, Wu H. 2011. Effect of the antimicrobial decapeptide KSL on the growth of oral pathogens and Streptococcus mutans biofilm. Int J Antimicrob Agents. 37:33-38.

Lynch AS, Robertson GT. 2008. Bacterial and fungal biofilm infections. Ann Rev Med. 59:415-428.

Maha TF, O'Toole GA. 2001. Mechanisms of biofilm resistance to antimicrobial agents. Trends Microbiol. 9:34-39.

Mahmoudi M, Serpooshan V. 2012. Silver-coated engineered magnetic nanoparticles are promising for the success in the fight against antibacterial resistance threat. ACS Nano. 6:2656-2664.
Maki DG. 2010. In vitro studies of a novel antimicrobial luer-activated needleless connector for prevention of catheter-related bloodstream infection. Clin Infect Dis. 50:1580-1587.

Martínez-Gutierrez F, Olive PL, Banuelos A, Orrantia E, Nino N, Sanchez EM, Ruiz F, Bach H, Av-Gay Y. 2010. Synthesis, characterization, and evaluation of antimicrobial and cytotoxic effect of silver and titanium nanoparticles. Nanomed Nanotechnol Biol Med. 6:681-688.

Martínez-Gutierrez F, Thi EP, Silverman JM, de Oliveira CC, Svensson SL, Vanden Hoek A, Sánchez EM, Reiner NE, Gaynor EC, Pryzdial EL, et al. 2012. Antibacterial activity, inflammatory response, coagulation and cytotoxicity effects of silver nanoparticles. Nanomed Nanotechnol Biol Med. 8:328-336.

Matsukawa M, Greenberg EP. 2004. Putative exopolysaccharide synthesis genes influence Pseudomonas aeruginosa biofilm development. J Bacteriol. 86:4449-4456.

Paddle-Ledinek JE, Nasa Z, Cleland HJ. 2006. Effect of different wound dressings on cell viability and proliferation. Plast Reconstr Surg. 117:110S-118S.

Park MV, Neigh AM, Vermeulen JP, de la Fonteyne LJ, Verharen HW, Briedé JJ, van Loveren H, de Jong WH. 2011. The effect of particle size on the cytotoxicity, inflammation, developmental toxicity and genotoxicity of silver nanoparticles. Biomaterials. 32:9810-9817.

Post JC, Hiller NL, Nistico L, Stoodley P, Ehrlich GD. 2007. The role of biofilms in otolaryngologic infections. Curr Opin Otolaryngol Head Neck Surg. 15:347-351.

Prabhakara PK, Raja S, Anuradhab PR, Sawantb SN, Doblea M. 2011. Biocompatibility studies on polyaniline and polyaniline-silver nanoparticle coated polyurethane composite. Colloids Surf, B. 86:146-153.

Sawada I, Fachrul R, Ito T, Ohmukai Y, Maruyama T, Matsuyama H. 2012. Development of a hydrophilic polymer membrane containing silver nanoparticles with both organic antifouling and antibacterial properties. J Membr Sci. 387-388:1-6.

Seil JT, Webster TJ. 2011. Reduced Staphylococcus aureus proliferation and biofilm formation on zinc oxide nanoparticle PVC composite surfaces. Acta Biomater. 7:2579-2584.

Stewart PS. 2003. Diffusion in biofilms. J Bacteriol. 185:14851491.

Stewart PS, Costerton JW. 2001. Antibiotic resistance of bacteria in biofilms. Lancet. 358:135-138.

Stewart PS, Franklin MJ. 2008. Physiological heterogeneity in biofilms. Nat Rev Microbiol. 6:199-210.

Stoodley P, DeBeer D, Lewandowski Z. 1994. Liquid flow in biofilm systems. Appl Environ Microbiol. 60:2711-2716.

Subbiahdoss G, Sharifi S, Grijpma DW, Laurent S, Van der Mei HC, Mahmoudi M, Busscher HJ. 2012. Magnetic targeting of surface-modified superparamagnetic iron oxide nanoparticles yields antibacterial efficacy against biofilms of gentamicin-resistant staphlococci. Acta Biomater. 8:2047-2055.

Sutherland IW. 2001. The biofilm matrix-an immobilized but dynamic microbial environment. Trends Microbiol. 9.222-227.

Teodosio JS, Simoes M, Melo LF, Mergulhao FJ. 2011. Flow cell hydrodynamics and their effects on $E$. coli biofilm formation under different nutrient conditions and turbulent flow. Biofouling. 27:1-11.

Ulkur E, Oncul O, Karagoz H, Yeniz E, Celikoz B. 2005. Comparison of silver-coated dressing (Acticoat), chlorhexidine acetate $0.5 \%$ (Bacti-grass), and fusidic acid $2 \%$ (Fucidin) for topical antibacterial effect in methicillin-resistant staphylococcoi-contaminated, full-skin thickness rat burn wounds. Burns. 31:874-877. 
Vieira MJ, Melo LF, Phinheiro MM. 1993. Biofilm formation: hydrodynamic effects on internal diffusion and structure. Biofouling. 7:67-80.

Walters MC, III, Roe F, Bugnicourt A, Franklin MJ, Stewart PS. 2003. Contributions of antibiotic penetration, oxygen limitation, and low metabolic activity to tolerance of Pseudomonas aenuginosa biofilms to ciprofloxacin and tobramycin. Antimicrob Agents Chemother. 47:317-323.

Wasche S, Horn H, Hempel DC. 2000. Mass transfer phenomena in biofilm systems. Water Sci Technol, 41:357-360.
Zelver N, Hamilton M, Goeres D, Heersink J. 2001. Development of a standardized antibiofilm test. Methods Enzymol. 337:363-376.

Zhang L, Gu FX, Chan JM, Wang AZ, Langer RS, Farokhzad OC. 2008. Nanoparticles in medicine: therapeutic applications and developments. Clin Pharmacol Ther. 83:761-769.

Zodrow K, Brunet L, Mahendra S, Li D, Zhang A, Li Q, Alvarez PJJ. 2009. Polysulfone ultrafiltration membranes impregnated with silver nanoparticles show improved biofouling resistance and virus removal. Water Res. 43:715-723. 